\title{
Characterization of Titanium Oxide Encapsulated

\author{
Zeolites and Its Photocatalytic Application for NO Decomposition
}

\author{
Shicheng ZHANG, Takaomi KOBAYASHI, Yoshio NOSAKA and Nobuyuki FUJI*
}

Received November 22, 1994 ; Accepted June 1, 1995

\begin{abstract}
Titanium oxide-encapsulated $\mathrm{X}$ and $\mathrm{Y}$ zeolites were prepared by ion exchange with $\left(\mathrm{NH}_{4}\right)_{2} \mathrm{TiO}_{2}\left(\mathrm{C}_{2} \mathrm{O}_{4}\right)_{2}$. The obtained zeolites were characterized by means of XRD, FT-IR, XPS, UV-vis and photoluminescence spectroscopies. By the introduction of $\mathrm{TiO}^{2+}$ ions, the zeolites exhibited adsorption and photoluminescence bands and became sensitive to UV irradiation. A high catalytic activity of NO decomposition was obtained at room temperature under UV irradiation. The major products in the presence of oxygen were $\mathrm{N}_{2}$ and $\mathrm{N}_{2} \mathrm{O}$. In reference experiments of $\mathrm{TiO}_{2}$ powder significant production of $\mathrm{NO}_{2}$ was observed.
\end{abstract}

\section{INTRODUCTION}

For the preservation of the global environment, some zeolite catalysts modified by $\mathrm{Cu}, \mathrm{Ga}, \mathrm{Pt}$ and $\mathrm{Ce}$ have been studied for decomposition of $\mathrm{NO}_{\mathrm{X}}$ under thermal conditions and in the presence of reductants ${ }^{1-4}$ ). For photocatalytic decomposition of NO, Anpo et al. reported the experimental results obtained by using $\mathrm{Cu}-\mathrm{Y}$ and $\mathrm{Cu}-\mathrm{ZSM}-5$ catalysts under irradiation of a high pressure mercury lamp5). They suggested that monovalent copper ions play a significant role in initiation of the NO decomposition. Furthermore, photocatalytic decomposition of $\mathrm{N}_{2} \mathrm{O}$ into $\mathrm{N}_{2}$ and $\mathrm{O}_{2}$ on degassed Cu-ZSM-5 zeolite or on $\mathrm{TiO}_{2}$-dispersed glass has been reported by Ebitani6) and Cant7). Since zeolite has the well-defined crystalline structure with the internal pore and cage, semiconductors such as $\mathrm{TiO}_{2}, \mathrm{CdS}$ and $\mathrm{ZnS}$ could be encapsulated in it. These modified zeolites subsequently exhibited photocatalytic properties $\left.{ }^{8-11}\right)$. The other titanium oxide catalysts reported so far were placed on porous vycor glass12), encapsulated in copolymer ${ }^{13}$, and mixed with silicon as binary oxide powder 14) or glass ${ }^{15}$ ). However, there were no reports on the photocatalytic decomposition of NO over these catalysts.

Department of Chemistry, Nagaoka University of Technology, (Kamitomioka, Nagaoka 940-21, Japan)

Key Words : Photocatalyst, X zeolite, Y zeolite, NO decomposition
In this report, titanium was introduced into the internal pores of $\mathrm{X}$ and $\mathrm{Y}$ zeolites by an ion-exchange method. The photocatalytic decomposition of NO over the modified zeolites was examined. Effect of the modification on the photocatalytic activity and selectivity are discussed.

\section{EXPERIMENTAL}

$\mathrm{Na}-\mathrm{X}$ and $\mathrm{Na}-\mathrm{Y}$ zeolites were kindly supplied from Mizusawa Chemical Engineering Co. Ltd. In order to introduce titanium into the zeolite pores, ion-exchange method was carried out by using $\left(\mathrm{NH}_{4}\right)_{2} \mathrm{TiO}\left(\mathrm{C}_{2} \mathrm{O}_{4}\right)_{2}$ as followed. A solution of $100 \mathrm{ml}\left(18.0 \mathrm{mmol} / \mathrm{dm}^{3}\right)$ of $\left(\mathrm{NH}_{4}\right)_{2} \mathrm{TiO}\left(\mathrm{C}_{2} \mathrm{O}_{4}\right)_{2}$ was used for treating $3.0 \mathrm{~g}$ of zeolite at 303 to $313 \mathrm{~K}$ for about 15 hours. The treated zeolites were washed with deionized water and dried at $393 \mathrm{~K}$ for overnight. After repeated the ion-exchange treatment, the zeolites were calcined at $793 \mathrm{~K}$ for 6 hours. The obtained zeolites were denoted as Ti-X and Ti-Y. The contents of titanium in the Ti-X and Ti-Y zeolites were $0.67 \mathrm{wt} \%$ and $0.63 \mathrm{wt} \%$, respectively.

The zeolite catalysts were characterized by means of XRD, FT-IR, UV-vis and XPS spectroscopies. The $X$-ray diffraction measurements were performed with a Rigaku RAD 3A goniometer. For FT-IR measurements, catalysts were ground with potassium bromide and then pressed into disks. The transmission IR spectra of the disks were measured with a JASCO FT-IR-5A. UV-vis diffuse reflectance spectra were taken at $298 \mathrm{~K}$ 
with a JASCO UNIDEC model 660 spectrometer equipped with an integrating sphere. An $\mathrm{Al}_{2} \mathrm{O}_{3}$ plate was used for the reference. Photoluminescence was measured at $77 \mathrm{~K}$ with a HITACHI model 850 instrument. The samples contained in Sprasil cell were immersed in liquid nitrogen in a Dewar vessel with quartz windows.

The photocatalytic reaction of NO was evaluated with a fix-bed flow reactor system. In the quartz reactor, a glass rod was installed to make the bed of the catalyst in the form of blank cartridge. This method increased the surface area of the bed which was irradiated with a high pressure mercury lamp. The reactant gas having $1.2 \% \mathrm{NO}, 1.0 \%$ air and $97.8 \%$ of $\mathrm{He}$ was used. The flow rate of the reactant gas was $4 \mathrm{ml} / \mathrm{min}$. The weight of the catalyst packed in the reactor was $0.8 \mathrm{~g}$.

The NO decomposition was analyzed by a gas chromatography ( Gasukuro Kogyo, model 370 ) using a molecular sieve $5 \mathrm{~A}$ column for $\mathrm{O}_{2}$, $\mathrm{N}_{2}$ and $\mathrm{NO}$, and a Porapak. Q column for the separation of $\mathrm{N}_{2} \mathrm{O}$.

The conversion of $\mathrm{NO}$ and the yield of $\mathrm{N}_{2}$ or $\mathrm{N}_{2} \mathrm{O}$ were defined by the following relations:

Conversion of $\mathrm{NO}=\left(\mathrm{M}^{0}{ }_{\mathrm{NO}}-\mathrm{M}_{\mathrm{NO}}\right) / \mathrm{M}^{0}{ }_{\mathrm{NO}}$

Yield of $\mathrm{N}_{2}$ or $\mathrm{N}_{2} \mathrm{O}=2 \mathrm{MN}_{2} / \mathrm{M}^{\mathrm{o}} \mathrm{NO}$

$$
\text { or } 2 \mathrm{MN}_{2} \mathrm{O} / \mathrm{M}^{\mathrm{O}} \mathrm{NO}
$$

where $M$ and $\mathrm{M}^{\circ}$ are the mole flow rates of the component indicated by the subscript at the outlet and inlet of photocatalytic reactor, respectively.

\section{RESULTS AND DISCUSSION}

\subsection{Characterization of titanium}

\section{- encapsulated zeolites}

The X-ray diffraction patterns of Ti-modified zeolites showed that the zeolites did not contain a detectable $\mathrm{TiO}_{2}$ phase. The crystallinity of the obtained zeolites was not affected by the ion exchange of $\mathrm{TiO}^{2+}$ and the calcination at elevated temperature.

Figure 1 shows IR spectra of $Y$ zeolite $(\mathrm{Na}-\mathrm{Y})$ and Ti-modified one (Ti-Y). After ion exchange with $\mathrm{TiO}^{2+}$, the $\mathrm{Ti}-\mathrm{Y}$ zeolite has a peak at $910 \mathrm{~cm}^{-1}$ in the spectrum. It was reported by Liu et al. that this is due to the introduction of $\mathrm{TiO}^{2+}$ ions ${ }^{11}$ ). A strong absorption band appeared near $1000 \mathrm{~cm}^{-1}$ is characteristic for zeolite framework. The shift of this band to the higher wavenumber side indicates that the $\mathrm{TiO}^{2+}$ ions were introduced

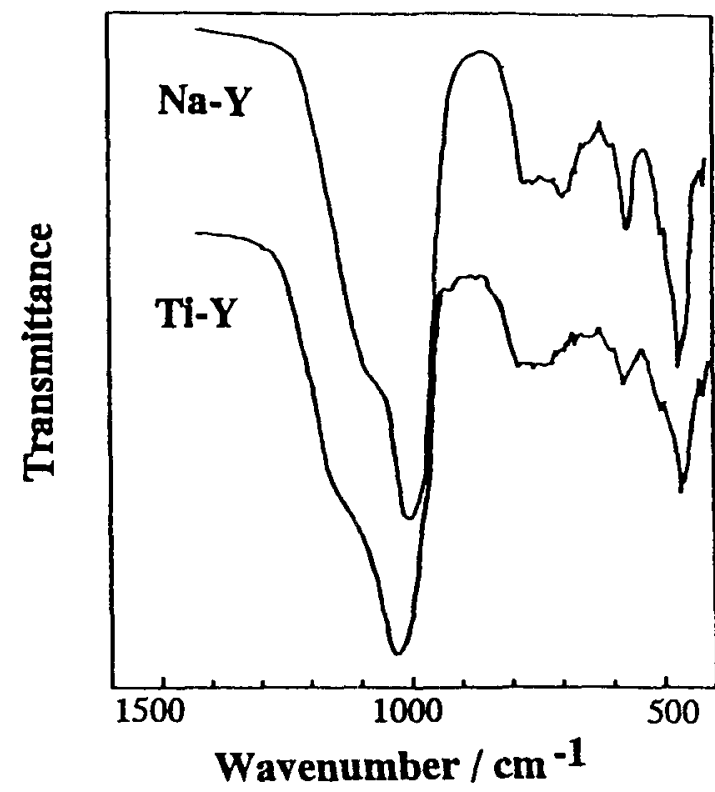

Fig. 1 FT-IR spectra of $\mathrm{Na}-\mathrm{Y}$ and titanium exchanged Ti-Y zeolites.

into the internal pores of zeolite. For $\mathrm{Na}-\mathrm{X}$ and Ti-X zeolites, their IR spectra are shown in Figure 2. The overlap of a broad peak in 550 -

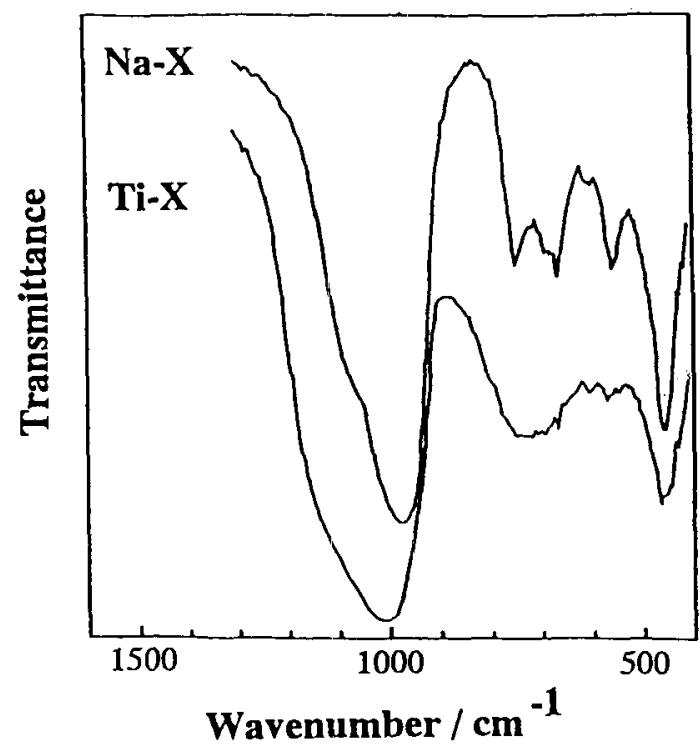

Fig. 2 FT-IR spectra of $\mathrm{Na}-\mathrm{X}$ and titanium exchanged Ti-X zeolites. 
$800 \mathrm{~cm}^{-1}$ region and the shift of the peak at $1000 \mathrm{~cm}^{-1}$ indicates a large interaction of $\mathrm{Ti}$ species with zeolites.

Figure 3 shows UV-vis reflectance spectra of the obtained zeolites and $\mathrm{TiO}_{2}$ powder $(74 \%$ anatase and $26 \%$ rutile). By the introduction of $\mathrm{TiO}^{2+}$ into the zeolite pores, the $\mathrm{Ti}-\mathrm{X}$ and $\mathrm{Ti}-\mathrm{Y}$ zeolites exhibited absorption with threshold wavelengths at 390 and $360 \mathrm{~nm}$, respectively. On the other hand, the absorption intensities of $\mathrm{Na}-\mathrm{X}$ and $\mathrm{Na}-\mathrm{Y}$ were small even in the wavelength region shorter than $300 \mathrm{~nm}$. The absorption intensity of Ti-X is higher than that of Ti-Y. The results of XPS experiments indicated that the titanium content on the surface of $\mathrm{Ti}-\mathrm{X}$ zeolite was about 2.2 times as much as Ti-Y zeolite. This observation was consistent with the large absorbance in the UV spectra of Ti-X. However, by comparing with $\mathrm{TiO}_{2}$ powder, the absorption for $\mathrm{Ti}-\mathrm{X}$ and Ti-Y zeolites was smaller in the intensity and shorter in the threshold wavelength. This result indicates that the differ ent circumstances in the zeolites affect the UV absorption with different interaction. The above observation in UV spectra was similar to that reported for the titanium-dispersed titanium silicate zeolite 19 .

Figure 4 shows the photoluminescence spectra of Ti-X and Ti-Y zeolites at $77 \mathrm{~K}$. For

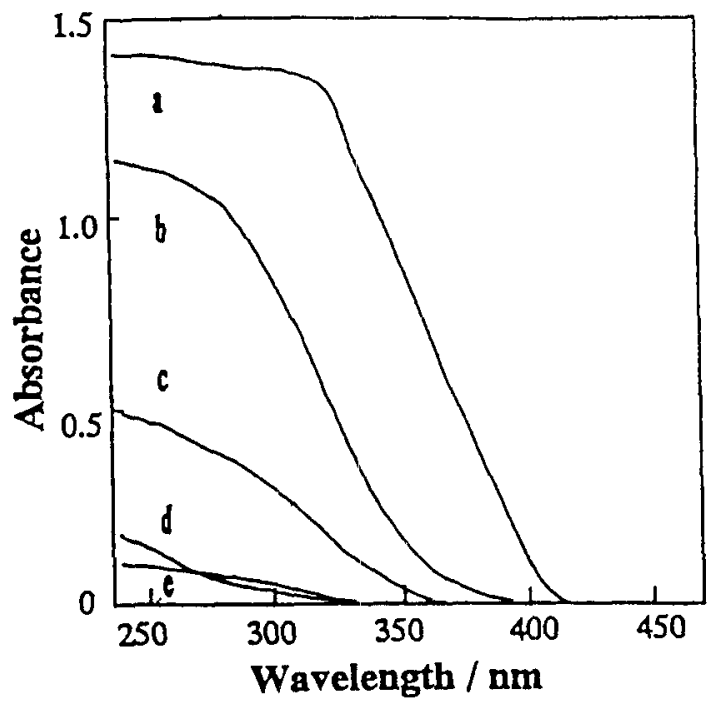

Fig. 3 UV-vis reflectance spectra of bulk $\mathrm{TiO}_{2}$ and zeolites.
(a) $\mathrm{TiO}_{2}$
(b) $\mathrm{Ti}-\mathrm{X}$
(c) $\mathrm{Ti}-\mathrm{Y}$
(d) $\mathrm{Na}-\mathrm{X}$
(d) $\mathrm{Na}-\mathrm{Y}$

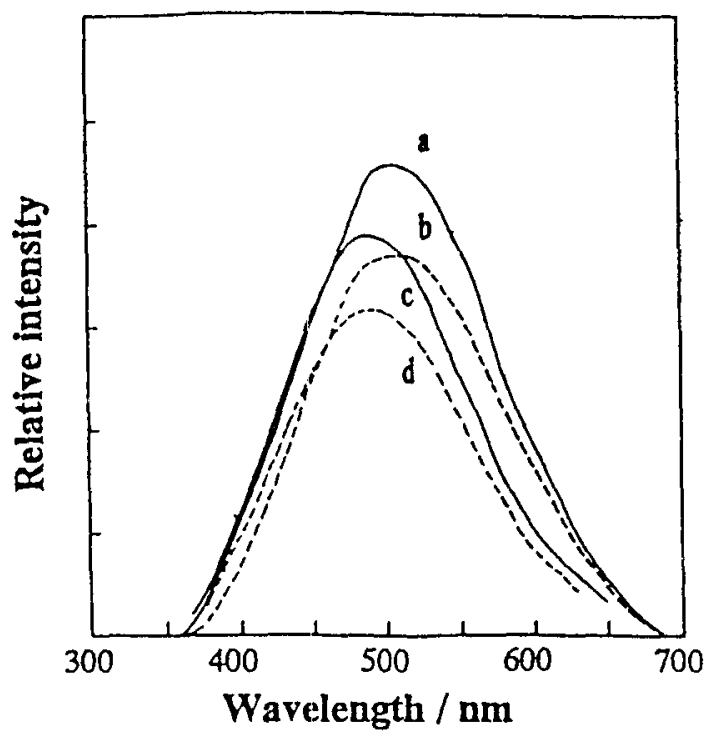

Fig. 4 Photoluminescence of titanium exchanged zeolites and the effects of adding $\mathrm{O}_{2}$ on zeolites.
(a) $T i-X$
(b) $\mathrm{Ti}-\mathrm{X}\left(\mathrm{O}_{2}: 20 \mathrm{kPa}\right)$
(c) Ti-Y
(d) $\mathrm{Ti}-\mathrm{Y}\left(\mathrm{O}_{2}: 20 \mathrm{kPa}\right)$

measurement: $77 \mathrm{~K}$, excitation: $240 \mathrm{~nm}$

the Ti-X zeolite, a peak in the emission spectrum appeared at $510 \mathrm{~nm}$, while for the Ti-Y, it appeared at a shorter wavelength of $490 \mathrm{~nm}$. The dispersion degree on the whole Ti-Y zeolite particle might be relatively larger than that on Ti-X zeolite, because the titanium content on the external surface layer of the $\mathrm{Ti}-\mathrm{Y}$ zeolite was smaller than that of $\mathrm{Ti}-\mathrm{X}$ zeolite and the total amount of titanium atoms was almost equal for both zeolites. The high dispersion may cause strong inter action of the titanium atom with the zeolite framework and may explain the shorter peak wavelength in the emission spectra and the smaller absorbance in the UV spectra. The same phenomenon was also observed in titanium-silicon binary oxide catalysts ${ }^{14)}$, where the photoluminescence of the binary oxide containing $0.3 \%$ titanium showed a smaller intensity and appeared at shorter wavelength compared with that containing $1.0 \%$ titanium. As shown by the broken line in Figure 4 , the photoluminescence of Ti-X and $T i-Y$ is somewhat quenched on the contact with $20 \mathrm{kPa}$ oxygen. Comparing with $\mathrm{TiO}_{2}$ powder, the quenching phenomenon of the $\mathrm{Ti}-\mathrm{X}$ and Ti-Y zeolites was similar to that observed for the titanium-silicon oxides ${ }^{14}$ ) and the titanium 
coated porous vycor glass ${ }^{15}$ ).

The different degree of the titanium disper sion might be caused by the differ ence of the ion exchange site in the $X$ and $Y$ zeolites and by the condensation of $\mathrm{TiO}^{2+}$ ions during the calcination ${ }^{11}$ ). In order to avoid the colloidal formation in the ion exchange procedure, $\left(\mathrm{NH}_{4}\right)_{2} \mathrm{TiO}\left(\mathrm{C}_{2} \mathrm{O}_{4}\right)_{2}$ salt was used to introduce the $\mathrm{TiO}^{2+}$ ions into the zeolites. However, it was not clear that on which site in faujusite the $\mathrm{TiO}^{2+}$ ions located.

\subsection{Photocatalytic activity for NO decomposition}

The experimental results of NO decomposition over the Ti-X, Ti-Y and $\mathrm{TiO}_{2}$ catalysts are shown in Figure 5. The main products of the photocatalytic decomposition of NO were $\mathrm{N}_{2}, \mathrm{~N}_{2} \mathrm{O}$ and $\mathrm{O}_{2}$. The conversions of NO for Ti-X and Ti-Y zeolites were higher than that for $\mathrm{TiO}_{2}$. The yields of $\mathrm{N}_{2} \mathrm{O}$ observed for the $\mathrm{Ti}-\mathrm{X}$ and $\mathrm{Ti}-\mathrm{Y}$ zeolites tend to increase with the reaction time. The amount of $\mathrm{NO}_{2}$ formed was very small over $\mathrm{Ti}-\mathrm{X}$ and $\mathrm{Ti}-\mathrm{Y}$. However, the formation of $\mathrm{NO}_{2}$ was found

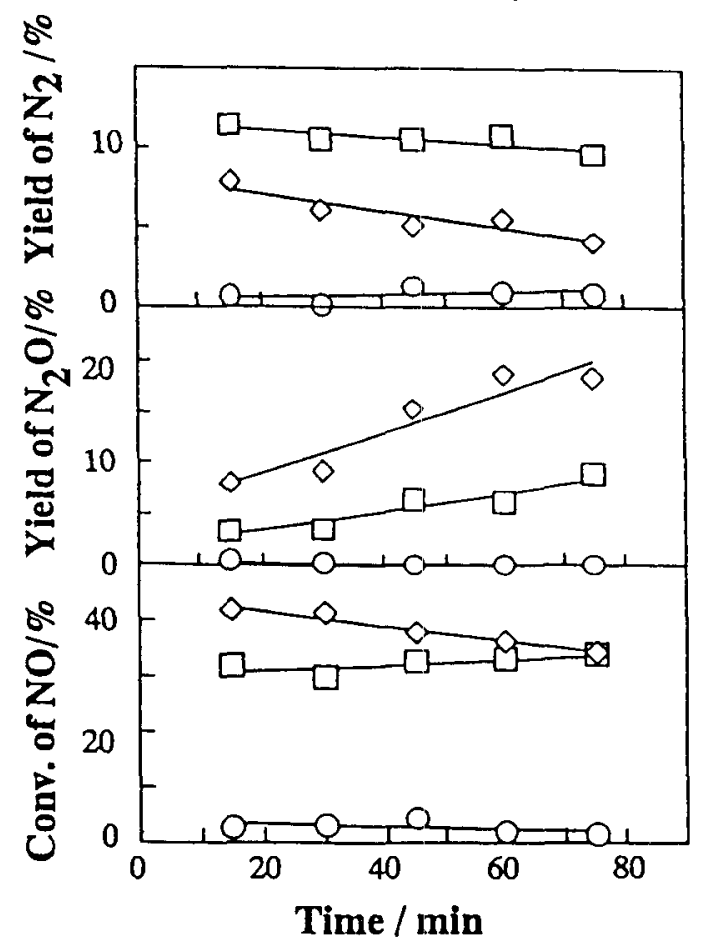

Fig. 5 Time profiles of the photocatalytic decomposition of NO on Ti-X ( $\square), T i-Y(\diamond)$ and $\mathrm{TiO}_{2}(\mathrm{O})$ catalysts under $\mathrm{UV}$ irradiation at $298 \mathrm{~K}$ in the fixed-bed flow reactor. three times as much as the formation of $\mathrm{N}_{2} \mathrm{O}$ over $\mathrm{TiO}_{2}$. On both modified zeolites and $\mathrm{TiO}_{2}$, a little amount of $\mathrm{O}_{2}$ was produced. For unmodified $\mathrm{Na}-\mathrm{X}$ and $\mathrm{Na}-\mathrm{Y}$ zeolites, no formation of $\mathrm{N}_{2}$ and $\mathrm{N}_{2} \mathrm{O}$ was found under the UV irradiation.

As shown in Figure 5, the zeolites encapsulated by titanium have high photocatalytic reactivity compared with that of the bulk $\mathrm{TiO}_{2}$. From the product components, it seems that the titanium-encapsulated zeolites mainly catalyze the reduction of NO, but the bulk $\mathrm{TiO}_{2}$ catalyzes the oxidation of $\mathrm{NO}$ under the present experimental conditions.

The high reactivity on the modified zeolite could be explained by that the coordinative unsaturated titanium atoms were highly dispersed onto zeolites. According to the results of XPS, UV-vis absorption and photoluminescence measurements, the surface content of titanium on the $\mathrm{Ti}-\mathrm{X}$ zeolite was larger than that on the Ti-Y zeolite. Since the efficiencies of the NO decomposition were almost same in the two types of zeolites, the decomposition reaction might occur not only on the external surface of zeolite, but also on the internal surface. On the other hand, the different selectivity in the photocatalytic decomposition was observed. The yield of $\mathrm{N}_{2} \mathrm{O}$ was larger on Ti-Y, while that of $\mathrm{N}_{2}$ was larger on Ti-X. In addition, it is noted that the high reactivity for the $\mathrm{T} i-\mathrm{X}$ and $\mathrm{Ti}-\mathrm{Y}$ zeolites was observed even in the presence of oxygen. The photoluminescence intensity shown in Figure 4 was not completely quenched even though they contacted with $20 \mathrm{kPa}$ of oxygen. It is probable that, under the irradiation condition, the encapsulated titanium gives its electron to the anti-bonding $\pi$ orbital of NO and assists the decomposition. Meanwhile, it is suggested that the produced oxygen species, such as $\mathrm{O}^{-}$and $\mathrm{OH}$, were not effective to react continuously with NO on the Ti-X and Ti-Y zeolites. On the other hand, the reactivity for NO decomposition over $\mathrm{TiO}_{2}$ powder was not so high as expected. Because the active oxygen species $\mathrm{O}^{2-}, \mathrm{O}^{-}$and $\mathrm{OH}$ could be easily generated on the irradiated $\mathrm{TiO}_{2}$ surface, NO tended to be oxidized to $\mathrm{NO}_{2}$ and nitrate ${ }^{17}$ ).

In conclusion, the ion exchange treatment with $\left(\mathrm{NH}_{4}\right)_{2} \mathrm{TiO}\left(\mathrm{C}_{2} \mathrm{O}_{4}\right)_{2}$ allowed titanium to 
disperse into the $\mathrm{X}$ and $\mathrm{Y}$ zeolites. Char acterization by means of XRD, FT-IR and other spectroscopies proved that titanium was introduced into the zeolites. The introduction of titanium caused the UV light absorption and photoluminescence. The modified zeolites had a high activity for the decomposition of NO compared with that of $\mathrm{TiO}_{2}$ powder at room temperature under the irradiation with UV light. The $\mathrm{N}_{2}, \mathrm{~N}_{2} \mathrm{O}$ and $\mathrm{O}_{2}$ were produced from NO on the modified zeolites. The present results suggest that the titanium modified zeolites have a possibility serving as a new type of material for NO photodecomposition.

The authors wish to give thanks to Prof. Y. Inoue, Dr. K. Sato, and Mr. M. Ohno of the analysis center of our university for their helps in the experiment.

\section{REFERENCES}

1) Y. Li and J. N. Armer, J. Catal., 145, 1(1994).

2) C. Yokoyama and M. Misono, Bull. Chem. Soc. Jpn., 67, 557 (1994).

3) H. Hirabayashi, H. Yahiro, N. Mizuno and M. Iwamoto, Chem. Lett., 1992, 2235.

4) K. Yogo, M. Ihara, I. Terasaki and E. Kikuchi, Chem. Lett., 1993, 229.

5) M. Anpo, M. Matsuoka, Y. Shioya, H. Yamashita, E. Giamello, C. Morterra, M. Che, H. H. Patterson, S. Webber,
S. Ouellette and M. A. Fox, J. Phys. Chem., 98, 5744, (1994).

6) K. Ebitani, M. Morokuma, J. H. Kim and A. Morikawa, J. Catal., 141, 725(1993).

7) N. W. Cant and J. R. Cole, J. Catal., 134, 317(1992).

8) Y. Nosaka, Shokubai, 36, 507(1994).

9) Y. Wang and N. Herron, J. Phys. Chem., 91, 257(1987).

10) X. Liu and J. K. Thomas, Langmuir, $5,58(1989)$.

11) X. Liu, K. Iu and J. K. Thomas, J. Chem. Soc. Faraday Trans., 89, 1861(1993).

12) M. Anpo, N. Aikawa, Y. Kubokawa, M. Che, C. Louisand and E. Giamello, J. Phys. Chem., 89, 5017(1985).

13) H. Miyama, N. Fujii and Y. Nagae, Chem. Phys. Lett., 74, 523(1980).

14) M. Anpo, H. Nakaya, S. Kodama, Y. Kubokawa, K. Domen and T. Onishi, J. Phys. Chem., 90, 1633(1986).

15) M. Aizawa, Y. Nosaka and N. Fujii, J. Non-cryst. Solids, 168, 49(1994).

16) S. Yamagata, K. Mineo, N. Murao, S. Ohta and I. Mizoguchi, Denki Kagaku, 59, 87(1991).

17) T. Ibusuki, S. Kutsuna and K. Takeuchi, "Photocatalytic Purification and Treatment of Water and Air " (Ed. D.F. Ollis and H. Al-Ekabi), Elservier, Amsterdam, P. 375(1993). 